\section{PRELIMINARY REPORT}

ox

\section{ANIMAL VACCINATION IN ITS RELATION TO PROPOSED LEGISLATION.}

By ERNEST HART, EsQ.,

Chairman of the Parliamentary Bills Committee of the British Medical Association.

\begin{abstract}
Recent History of the Qucstion in England.-Objects of the forthcoming Conference. - Preliminary Remarks. - Historical Note on the Origin and Progress of Animal Vaccination in Europe and America.-Present State of the Question in Foreign Countries.-Statement of and Examination into Alleged Objections to Animal Vaccination.-Suggestions for Future Action.
\end{abstract}

BY the introduction last session into the House of Commons of Dr. Cameron's Bill providing for the supply of animal lymph as an alternative to humanised lymph for the vaccination of children whose parents have conscientious objections to the latter, the attention of the Parliamentary Bills Committee was particularly directed to a subject which has engaged professional and public attention for a considerable period. With a view to procuring for the Committee all needful information for its guidance in taking a course of action on this important subject, it seemed to me desirable that the arrangements which have been in force for several years in Belgium should be carefully studied, in order that their adaptability to our English system might be considered; and for that purpose I have on two occasions visited the animal vaccination bureaux at Brussels. It seemed, moreover, desirable that, pending the reintroduction of Dr. Cameron's Bill into Parliament next session, a Conference of those interested and of those specially experienced in the subject should be held, with the view of eliciting an expression of opinion from those best qualified to judge as to the most desirable course to be pursued with regard to Dr. Cameron's Bill, and the general subject of the official recognition in this country of animal lymph. With the sanction of the Committee, this Conference has now been arranged to be held on the $4^{\text {th }}$ December proximo, and there is reason for hoping that the results of its deliberations will have an important bearing upon the future of vaccination in this country. In addition to Dr. Cameron, M.P., who will attend to explain the motives and provisions of his Bill, Dr. Warlomont of Brussels has, with characteristic kindness, promised to come over expressly from Belgium to give us the benefit of his valuable experience, ranging over a long series of years, and many thousands of vaccinations, and to read a paper on the general subject. We are also promised the attendance of men so distinguished and specially informed as Sir Thomas Watson, Mr. John Simon, Mr. Ceely of Aylesbury, Dr. Robert Cory, Mr. John Greene of Birmingham, Dr. Braidwood of Birkenhead, and others, who have all devoted considerable attention to the subject before us. I am happy to add that the President of the Local Government Board, recognising the importance of the Conference, has most kindly offered to send one of the Board's Medical Inspectors (from whom we shall doubtless learn more particularly what are the official views upon this question) to represent the Department on this occasion.

In order to present to the Committee, and through them to the Conference, as complete an account as possible of the progress which animal vaccination is making throughout the world, I have collected together such statistics and information on the subject as I have been able to discover. I feel, however, that this information is still imperfect ; and I would suggest for the consideration of the Committee whether it would not be desirable to move the President of the Local Government Board to procure, from our representatives abroad, official and more complete information on the subject of the practice of animal vaccination in the countries to which they are accredited. The particulars which I have been able to collect will, however, be sufficient, I feel little doubt, to convince the Committee of the importance of some steps being taken to secure the official recognition of animal vaccination in this country.

This subject of animal vaccination has not been seriously discussed before the British Medical Association since its meeting at Leeds in 1869. I do not on the present occasion intend to deal at any length with the in many respects, interesting discussion that then took place; but I may refer in the briefest fashion to its results. ${ }^{*}$ The subject was started by Dr. Blanc with some enthusiasm, but with statistics which were much questioned, and which were certainly deficient in exactness; and he was followed by Drs. Braidwood, Ballard, and Druitt, all of whom expressed themselves in favour of the use of calf-lymph. Dr. M. K. Robinson, then Medical Officer of Health for Leeds, expressed a judicious caveat as to the decrying of arm-to-arm vaccination, for which the late Mr. A. B. Steele of Liverpool argued strongly. Mr. Steele's position can easily be understood. As one of the very best vaccinators of the staff of the National Vaccine Establishment, and as Teacher of Vaccination for Liverpool, he, of course, found arm-to-arm vaccination in his careful and judicious hands to be sufficiently successful.

At the time of this discussion in Leeds, animal vaccination was but little esteemed, either in this country or abroad ; and the results at that period of the use of calf-lymph were certainly not so satisfactory as te warrant the disturbance of the arrangements for arm-to-arm vaccination in England, which had been perfected at great trouble and expense only a short time before. It was therefore not surprising that Dr. Seaton, to whom we are indebted more than to any one else for our present excellent system of public vaccination in England, should have reported in 1869 adversely to the official recognition of animal vaccination by the Government.t But, since that time, changes of the most crucial and important kind have been effected in the conduct of animal vaccination abroad; so that now its supporters maintain that not only are its local effects equal to that of humanised vaccination, but greatly superior to them. The Government, however, as represented by the Local Government Board, have consistently refused to admit this, swayed, no doubt, by the very strong opinions which Dr. Seaton is known to hold on the subject. I desire to speak with the very greatest deference of Dr. Seaton's views in this matter; but I feel bound to say that the now available information leads to conclusions much opposed to those at which, as Dr. Mouat, one of the medical inspectors of the Local Government Board, stated at the recent congress at Amsterdam, Dr. Seaton has arrived after a recent review of the subject. It is a matter of extreme regret that Dr. Seaton will be unable to attend the Conference, as his great experience and the careful inquiries into the subject which he has on two occasions instituted would have made his presence most valuable and important; but I hear from Mr. Sclater Booth that he is now incapacitated by illness from attending to business. The President of the Local Government Board, who has most courteously expressed his great desire to facilitate the discussion at the Conference, and his readiness, under different circumstances, to furnish the Association with the results of Dr. Seaton's examination into the Belgian system of vaccination, informs me that those results are now before him in only an incomplete form, as he has but a short memorandum on the subject from Dr. Seaton, and it is impossible now to refer it to him for completion. However, it would appear from Dr. Mouat's statement that Dr. Seaton is still not convinced that animal vaccination as practised on the continent is superior to, or presents greater success than, the procedure adopted in England. Holding these views, and committed as he is, Dr. Seaton's refusal to substitute animal vaccination for what he considers the perfect system practised under his care is readily explicable. But it is still, in my opinion, to be regretted that he should have advised the Local Government Board to refuse animal vaccination as an alternative which would induce many people to submit to vaccination and revaccination who now (absurdly, if you will) object to it. There can be little doubt that, when Dr. Seatcn made his historic report on animal vaccination in the year 1869 , there was not much to be said for animal vaccination as then practised. $\mathrm{He}$ showed clearly enough that it was then altogether inferior to the system practised in this country, because it was impossible to keep up the stock, which had repeatedly failed, especially in Holland ; and because the percentage of unsuccessful vaccination was enormously greater than that obtained under our English system. The alleged superiority of calf over humanised lymph, that syphilis could not be invaccinated with it, was scouted, because it had apparently been proved to demonstration that syphilis could not be introduced into the system in this way. Against this adverse report of 1869 , which is being officially depended on and quoted as though its facts were equally applicable at the present day, we have the following. During the ten years which have since elapsed, Dr. Warlomont, at the head of a large animal vaccine establishment in constant operation, has never had the smallest difficulty in keeping up his succession of vaccinifer calves. The same experience comes from other countries. No difficulty is now found by Dr. Martin in

* See British Medical Journal, vol. ii, i869, pages 275-278.

$\dagger$ Twelfth Report of the Medical Officer of the Privy Council for I869, pp. I7I-Igr. 
America, or by the heads of the vaccination bureaux in Holland, Berlin, or Milan. Dutch statistics show the number of failures in primary vaccinations to be under one per cent. ; and, in revaccinations, animal lymph has been shown to "take" much better than humanised lymph. The evidence as to the possibility of the invaccination of syphilis has now satisfactorily established that, although happily infinitely rare-so much so, as to be beyond all calculation-nevertheless such invaccination is possible.

M. Warlomont has stated that, when he suggested to the official adviser of the Local Government Board that an experimental station should be established in London for animal vaccination, the latter refused on the ground that "everyone would flock there". Surely this admission is very damaging. If everyone would flock there, this is an unanswerable argument of those who contend that, cateris paribus, that is, if animal vaccination be equally effective, a compulsory law should also allow some play to such rooted prejudice.

All the members of the Medical Department of the Local Government Board are not, however, opposed to the introduction of animal vaccination. I have the authority of Dr. Cameron for saying that Mr. Simon, the late eminent Medical Officer of the Privy Council and Local Government Board, declared that, if he had remained in office, he would have introduced animal vaccination; and I will only give, in addition, the remarks made in 1868 by Dr. Ballard-now one of the most distinguished of our Government medical inspectors-after an inspection of even the imperfect results at that time attained. After alluding to the number of cities in which the practice of animal vaccination had taken root, Dr. Ballard says : " It is difficult to account for its adoption in so many places, except on the ground that some real advantage attaches to it. I confess that I should be glad to see animal vaccination adopted in this country as a part of our national arrangements for the prevention of small-pox. I believe that good would result from it; if no other good, there would be this: that practitioners who are dissatisfied with the virus they are using might have recourse to the vaccinated heifer at any time for the improvement of their supply. It would not necessitate or even render desirable the abandonment of arm-to-arm vaccination ; but its adoption would tend to meet the prejudices of some persons who decline now to avail themselves of vaccination on account of the dangers with which they believe it is surrounded."

The late Mr. J. F. Marson, for many years the chief vaccinator to the Privy Council, and subsequently to the Local Government Board, whose knowledge of the subject of vaccination was of the highest order, and whose practical experience of the operation was greater than that of almost any other man in the profession, stated before the Select Committee of the House of Commons in I87 I that he thought animal vaccination would be a very good plan; and that he had himself, in June 1869, successfully vaccinated thirteen children from an inoculated heifer brought to the National Vaccine Establishment station in the Blackfriars Road. $t$

One great object of the Parliamentary Bills Committee in convening the forthcoming conference has been to attempt to get at the general opinion of medical men in England upon this important subject. I believe I am correct in stating that, outside the official medical world, there are very few of our profession who have any positive objections to urge against animal vaccination. On the other hand, those who have taken the trouble to inquire into the subject on their visits to the continent, have, I think, uniformly been struck, as I have been, with the simplicity and efficiency of the arrangements made at the various stations at which animal vaccination is in force, and their adaptability to our English system. I shall not now recount the opinions of those who have studied the subject, but shall content myself with a brief reference to what Sir Thomas Watson, the Nestor of our profession, has said in the able paper recently contributed by him to the Ninetcenth Century, and since republished in a separate form. $\neq$ Sir Thomas Watson, after alluding to the "ugly blot" which has fallen "upon this fair and priceless charter of safety to humanity", vaccination, describes the arrangements made at Brussels under the able superintendence of Dr. Warlomont, and proceeds, "Surely similar institutions might be formed in London, and in all the large towns of this rich kingdom, whereat the general public might obtain vaccination from the baby or from the calf at their pleasure, while compelled vaccinations should in all cases be from the calf alone. It seems to me that all this could be effected under the authority and control of the Local Government Board, without derogation from the status or the emoluments of our licensed vaccinators, and therefore without opposition on their part."

* Prize Essay on Vaccination. By Edward Ballard, M.D. Page 253.

$\uparrow$ Report of the Select Committee on the Vaccination Act of 1867 , Questions 470x-2.

$\ddagger$ The Abolition of Zymotic Diseases. By Sir Thomas Watson, Bart., M.D., F.R.S. London; C. Kegan Paul, and Co. 1879 . (See pages 145.153.)
This view will, I am sure, find an echo in the mind of every member of this Committee.

After these preliminary remarks, I propose, in the first place, to show the progress that animal vaccination is making in the estimation of other countries than our own; then to state what appear to me to be valid answers to objections which have been raised to the use of calflymph; and finally, to indicate what, in my opinion, are the steps necessary to be taken to place this country, the birthplace of vaccination, on a level with other countries as regards the perfection of its machinery for securing the general vaccination of the population.

\section{I.-Origin and Progress of Animal Vaccination* in} EURope, INDIA, AND AMERICA.

Shortly after the introduction of vaccination into Italy, Troja, of Naples, conceived the idea of taking the vaccine virus from the vaccinated cow for the purpose of human vaccination, and the practice was pursued by him and his successors during many years for the benefit of the upper classes of society. On the death of Troja, Galbiati, his successor, continued it; and although in 1810 these vaccinations were proscribed, yet in the same year, we are told, several distinguished statesmen availed themselves of this method for their own children. Galbiati, who is reported to have become insane through the bitter opposition and ridicule of his scheme which he experienced, and to have terminated his life by suicide, was followed by M. Negri, who had to bear the brunt of official opposition similar to that offered to his predecessors. It is to $M$. Negri that we owe the practice of animal vaccination as it is understood now. Troja and Galbiati had both propagated in the heifers a vaccine disease implanted upon them originally from a human source. In fact, what they practised was a retro-vaccination, the result of which was perpetuated through a series of animals. At first, M. Negri followed in their steps, but subsequently, on the occasion of an outbreak of cow-pox in Calabria, the use of this virus was abandoned, and M. Negri propagated henceforth that obtained from the natural cow-pox. It is said that, on three occasions, he thus availed himself of natural cow-pox, on each occasion maintaining the supply by an uninterrupted succession of inoculations from animal to animal. At the date of Dr. Ballard's first inquiry in I867, so thoroughly had all the prejudices upon the subject been cleared away, that $M$. Negri vaccinated from the heifer, in the course of a year, from 3,000 to 4,000 persons, a number nearly equal to the annual births that take place at Naples; and for several years M. Bima, of the Italian army, had used the animal vaccine alone for his regimental vaccinations, and for the pupils of the military colleges.

In 1864, Dr. Palasciano of Naples addressed the Medical Congress at Lyons on the subject of the vaccinations practised by his townsman Negri. So impressed was one of his listeners, Dr. Lanoix, that he visited Naples, studied animal vaccination under Negri, and presented, in a memoir to the French Academy, the facts he had collected on the subject. On his return, he brought with him a vaccinated calf, and after introducing the practice of animal vaccination at Lyons, established it in Paris under the auspices of M. Depaul, the director of vaccine. From Paris, the practice of animal vaccination has extended in many directions, amongst the first to take up the question being Dr. Warlomont, of Brussels (February 1865), and Dr. Pissin, of Berlin (June 1865 ), both of these being private speculations. Subsequently, the ramifications became so extensive, that it is impossible to follow them, and the practice is now in force, not only in France and Italy, but in Belgium, Holland, Germany, Russia, Spain, Austria, Switzerland, the United States, and in our own Indian empire at Bombay and elsewhere. Below are given the salient points of the information communicated to me with regard to each of these countries.

FRANCE.-I have already referred to the introduction of animal vaccination in Paris by Dr. Lanoix, who, in conjunction with M. Chambon, set up in 1864 a private establishment for the propagation of the virus from calf to calf. In 1866, the French Government placed the sum of six thousand francs at the disposal of the Académie de Médecine for the purpose of experiments in the matter; and subsequently a Commission reported in favour of the practice of animal vaccination. At first, the virus used by the Commission was that of MM. Lanoix and Chambon; but, after four transmissions of this virus had been made, a new source from natural cow-pox was discovered at Beaugency (Loiret), in favour of which the Neapolitan virus was abandoned. MM. Lanoix

* The term " animal vaccination" has not unfrequently been misunderstood to mean something which it is not. It may therefore be desirable to explain that throughout something which it is not. It may therefore be desirable to explain that throughout
this report the term is used to mean what Dr. Martin correctly describes as "the
inoculation of a young selected animal of the bovine species, from an original sponinoculation of a young selected animal of the bovine species, from an original spon-
taneous case of cowpox, from this others, and so on in continuous and endless series, as a source of virus to be used for the protection of the human race from variolous disease." 
and Chambon also adopted the use of this virus; and having in the same year (1866) met with another case of natural cow-pox at St. Mandé, near Paris, they introduced this lymph also into their practice. The establishment of these gentlemen is a private one; but M. Lanoix has, since the summer of 1865 , held an appointment from the Directeur de l'Assistance Publique for the weekly performance of vaccinations at the hospitals at Paris, from the calves which he inoculates week by week. By far the larger number of vaccinations and revaccinations performed in these establishments are done in this way. During the Franco-Prussian War and the siege of Paris, animal vaccination ceased in that city for very obvious reasons. The last virus carried from Paris was that taken by Dr. Martin's agent to America; and, during the siege, the "stock" was lost. The virus employed since the war has been from other stocks discovered since that of Beaugency. The mode of procedure at Paris is as follows. The animals used for the purpose are calves of the age of from four to eight months. Animals with white skins and females are preferred. Those used are such as are brought to the market for the purpose of slaughter; and no difficulty has been experienced in making an arrangement with a butcher for a constant supply of them at a price previously agreed upon, and for their repurchase. Such calves, coming to the Paris market, are generally weaned calves ; and, even when they are not, no great difficulty in feeding them is generally experienced by persons accustomed to the management of such animals. They are carefully stabled, and fed as nearly as possible upon the diet to which they are accustomed; and, when done with, they are returned to the butcher for slaughter. A vaccinating table of convenient construction is provided. It is a strong wooden table, with a flap, which is cut out semicircularly in the middle, so as to correspond in shape roughly with that of the body and legs of the animal. The flap being let down, the calf is placed with its left side against it ; and, being then securely fastened, the flap is raised horizontally, so that the animal lies with the right side uppermost. The operator then proceeds to shave, with a dry razor, the right side of the abdomen, commencing from the udder, and extending over a space of about ten inches long by six or eight broad. The calf which is the vaccinifer, from which the virus is to be taken, is also securely fastened down in a similar manner. upon the floor, and the vaccine matter is obtained from the pock by forcible compression of its base with a pair of spring forceps. The result is the rupture of the pock, and an abundant How of a thickish fluid, which is taken upon the lancet or into capillary tubes for the purpose of preservation. The animal upon the table. is vaccinated upon the shaven surface by puncture in sixty or seventy places, a little turn being given to the lancet at each puncture, and means are adopted to prevent subsequent injury by biting or licking. Pocks, which finally attain the size of large human vaccine pocks, speedily begin to rise, and are used for the vaccination of children from the fourth to the sixth day. After this day, the vaccine they contain is found to be less active, but still sufficiently so for the vaccination of another calf, for which the pocks left unopened are, therefore, used on the seventh or eighth day. The method of obtaining the vaccine matter just described is different from that followed by $M$. Negri in Naples. His practice is, or was, to slice off the entire pustule with a lancet, and then, taking it in his fiugers, to scrape the attached surface, so as to obtain a magma of lymph and dermal tissue. This method is still followed at Milan and other Italian stations; and the lymph so obtained is mixed with glycerine, and largely used in loco, as well as for export demands.

With the exception of the necessary interval during the FrancoPrussian War, I believe M. Lanoix has never once failed in his attempts to continue the cow-pox by inoculation. In some animals, the eruption might be finer, in others poorer ; but the genuine disease was always produced; and, whatever the eruption on the animal, it made little or no difference as to the effects of the lymph on the human subject, nor as to its effects when transmitted to another animal. At first, only one calf was vaccinated per week; but, since the latter part of 1865 , two calves have been kept weekly under inoculation, the one being vaccinated on Friday, and the other on Saturday.

In a recent communication to the French Academy of Medicine, Dr. Pietra Santa, the accomplished editor of the Fournal d'Hygiene, who has devoted much attention to the subject of animal vaccination, stated the reasons which had induced the Société Française d'Hygiène to patronise the establishment at Paris of a vaccination station, provided with both sorts of lymph.* An attempt was made to vaccinate the children brought for vaccination with humanised lymph on one arm, and animal lymph on the other. This, however, had to be discontinued, in consequence of the very general preference of the mothers for animal vaccination. The ascertained results attained by the Society

* See Journal d' Hygiène for October 9th and 16th, 1879. are not of sufficiently exact a nature to warrant any definite conclusions being drawn from them; but they bear out the general principle enunciated by Dr. Pietra Santa, that animal vaccination is a good, useful, and efficacious method of vaccination, as evinced by the results of the numberless vaccinations that have been performed with it.

BELGIUM.-For the sake of completeness, I append a brief history of the growth of animal vaccination in Belgium, leaving the statement of the measure of success attai ned in that country with calf-lymph to the able hands of Dr. Warlomon t at the forthcoming Conference. When Dr. Warlomont introduced a nimal vaccination into Brussels in February 1865 , his first supply o virus was from the Neapolitan source; but, after that, he obtained the Beaugency virus, and in July 1868 introduced the Esneaux (Liége) lymph. In September 1866, at the request of the Minister of the Interior, the Royal Academy of Belgium referred the whole question to a commission, who reported favourably of it. In July 1868, an Institut Vaccinal de l'État was established by royal decree at Brussels, under the direction of Dr. Warlomont, for maintaining the practice of animal vaccination, and distributing gratuitously the lymph obtained from the animals. The Institute is attached to the Zoological Garden at Brussels, and consists of two waiting-rooms; one for applicants who pay for their vaccination; and the other, larger, for those who are vaccinated gratuitously. There are also two other rooms appropriately fitted up, one of which communicates directly with a stable capable of containing six calves. The calves are brought regularly, as wanted, by a butcher, who lets them to the institute for a term of seven days, after which they are returned to him. As a rule, two calves per week suffice. I purposely do not go into details with regard to the method of vaccinating the calves, or of taking the lymph, as this will come better from Dr. Warlomont; nor do I go at length into th statistics of success, to which Dr. Warlomont will draw attention at the Conference. But I cannot refrain from quoting what to my mind is one of the strongest evidences in favour of animal vaccination that we havenamely, that among more than ten thousand children vaccinated at Brussels from 1865 to 1870 , and living afterwards amidst the terrible epidemic of small-pox of 1870 and 1871 , there was not known a single instance of an attack of small-pox; and the same absolute immunity from that disease was enjoyed by the far greater number of revaccinated persons living under similar conditions. ${ }^{*}$ Animal lymph is also used for the vaccinations performed under the direction of the Brussels Board of Health. This lymph comes from Milan in quills, and is highly spoken of by Dr. Janssens, the Chief of the Health Department in Brussels.

HollaND.-In Holland, the practice of animal vaccination is very largely developed. At the present time, there are four permanent institutes, at Rotterdam (founded in I868), at Amsterdam (1869), The Hague (1871), Utrecht (1872) ; besides three temporary stations, working only in summer, at Kampen, Haarlem, and Groningen. In the Netherlands, it is customary to make ten punctures; and if, after five days, there be fewer than four pocks, a few punctures more are made with the lymph of the same child [auto-revaccination]. Dutch experience is the same as that of other countries, that animal lymph in tubes cannot be kept so long as human lymph; in fact, that it loses its efficacy from day to day. $t$ It is found that lymph mixed with glycerine has the same effect. In Rotterdam, tubes are employed; but, in Amsterdam and Utrecht, glass plates, closed with sealing-wax or soldered, have been used. The use of these latter is, however, very properly, being more and more abandoned. At the Hague, pure lymph has been found more efficacious after a time than that mixed with glycerine. Calf-lymph is largely exported from Holland to its colonies, etc.; and some sent to the East Indies in 1876 came back without any impairment of its efficiency. The transport of the lymph is undertaken by the Government, and it is carriage free throughout the kingdom. The calculation has been made that an establishment where two calves are inoculated per week would cost four thousand francs a year, excluding the vaccinator's fees. All the Dutch stations are open once a week for gratis vaccination, and once a month for vaccinations which are paid for. The number of the latter is very inconsiderable, almost the whole population availing themselves of free vaccination. The deficit at all the stations is covered more or less by the State or the Province.

Dr. Carsten stated at Geneva in 1877 , that, after nine years of experience in animal vaccination, they had arrived in Holland at such perfection that they could compete in every respect with the best institutes vaccinating with human lymph. As in other places, the results were at first disappointing; but this has now been completely changed. From a vaiuable table compiled by Dr. Carsten with regard to the statistics of the four permanent stations, I take the following facts.

Compte Rendu du Congrès Pêriodique International des Scicnces Médicales, $4 \mathrm{me}$ Session, à Bruxelles. 1875 .

+ See Dr. Carsten at the Geneva International Congress, 1877 . 
The percentage of failures has gradually dwindled from 18.5 in 1869 to $8,4.6,1.6,1.2,1.3,1.0,0.8$, and 0.09 , in subsequent years, ending in 1877 . Thuring the ten years $1868-77$, a total of 22,8 ro humanised vaccinations and revaccinations, and 39,864 animal vaccinations and revaccinations, were performed. Of the 29,465 animal vaccinations, 28,862 were succes ful, and 603 were unsuccessful. In i $\$ 77$, the number of animal vaccinations was, at Rotterdam, $2,3_{3}{ }_{3}$; at Amsterdam, 2,905; and at the Hague, 2,454. The talble shows very clearly the very large decline in vaccinations performed with humanised lymph year by year since the introluction of animal vaccination; the relative numbers heing 2,024 (humanisel) and 744 (animal) in 1869 , against 1,467 (humanised) and 8,032 (animal) in 1877 .

Rotterdam.- Early in IS6S, the Society for the Promotion of Cowpox Inoculation at Rotterdam, " (ienootschap tot bevordering van de Koepokinenting te Kotterdam", by which the public vaccination of that city has been conducted since 1799, determined to open a station for the practice of animal vaccination, and such station has been in operation since April I\$6\$. The Rotterdam Association was founded in I799 for the proparation of cow-pox, and the first name inscribed on its list of honorary members is that of Edward Jenner. It has, since its foundation, performed the public vaccinations of Rotterdam at a station in the centre of the town, and distributed lymph through Ifolland and its colonies. It was with the view of obviating, by all possible means, any scruples or prejudices of parents, that the Society determined to add to its existing station a second for the performance of animal vaccination. The latter was at first practised with one calf weekly; but, since IS7I, two calves each weck have been regularly employed. These calves are inoculated - the one on the Tuesiay, the other on the Wednesday. The calf of Tuesday is inoculated direct from the calf of the preceding Wednestay, and serves for the vaccination of children on the Sunday following. The calf of the Wednesday is inoculated with lymph collected on the sunclay from the calf of the Tuesday of the weel before, and serves for the vaccination of children the Monday following. The vaccinations of the human subject with animal lymph are performed on Sundays and Montays only, and in each case with lymph at the sixth day of eruption. The propargation of the cow-pox on the heifer is done always with lymph collecter at the sixth or seventh day. To obtain the lymph, Dr. Minderap, the superintendent at the station, adopts the method of compressing the pock on the calf with pincers. The results of this methol are stated to be satisfactory. From the report of the Rotterdam Society for $\mathrm{I}_{77}$, it appears that ten punctures are marle for the insertion of the virus into the human arm. The average number of resulting poclis was, in $1877,81 / 2 ; 1,367$ cases had ten pocks or more, 256 nine pocks, 290 eight pocks, i 50 seven pocks, 109 six pocks, and 206 having five pocks or less.

Amsteridan.-Animal vaccination was started here on March 3 Ist, 1869, by a Vaccination Society similar to that at Rotterdam. The station is now a very successful one. At first, only one calf was inoculated weekly, on the Wednesday, and directly from the calf of the week preceding-the human vaccinations being lone from it on the Monday and Tuesday of the week following, or the sixth and seventh days of eruption. One calf was, however, found inconvenient, as the lymph criuld not be ke; t up permanently, and renewals had frequently to be male from kotterkm. Lfter a time, the society had better success, particularly since two calves have been employed. At present, the medical staff give their services gratuitously. The growth of the use of calf lymph is well fhom by the fact that, whereas in IS69 there were I, 192 more vaccinations performed with humanised than with calf lymph, in IS 77 the number of animal vaccinations surpassed the humanised vaccinations by $\mathbf{I}, 906$.

The Hawal.-On June I Ith, I 87 I, a station was opened here, and its results now quite correspond with those of Amsterdam and Rotterdam. From the first, the transmission of lymph from calf to calf has been successful ; this being mainly due to the employment of two vaccinised calves. Since 1 S 72 , the method of Dr. Bereth has been followed, and it is reported to fieli avourable results, especially in the transmission of lymph from calf to arm. During the summer of $\mathrm{I} 877$, three calves were employed.

Ltrecht.- The animal vaccination station at this city was opened on Iuly 29 th, I $\delta_{73}$. Ifere calves are wed which are a little older, and which are not fed with milk. The lymph from these calves is not so brilliant in its results as that taken from younger calves, being much drier and crustier.

Haarlem has a vacciriation station in the stmmer, and it is hoped that it will soon be made a permanent one.

Irusy.-In this kingrom, there appear to be no fewer than fourteen animal vaccination stations, all instituted and kept up by the enterprise of private medical men. These are at Bologna, Milan, Bergamo,
Ancona, Genoa, Venice (2), Arezzo, Verona, Vicenza, Rome, Modena, Ravenna, and Rimini.

Milan is a great lymph-providing station, sending supplies not only to Italy, but to Austria and Belgium, notably to Brussels, to the Board of Health there. Iuring the first half of 1877 , the latest period for which I have statistics, there were performed at Milan 2,733 vaccinations; the proportion of success being 99.70 per Ioo vaccinations, and 3,169 revaccinations, with a percentage of success of 47.05 per 100.* From I 869 up to 1877 , the number of vaccinations performed by the Milanese Committee had exceeded I00,000, and 665 heifers had been inoculated. The ideas of the Milanese Committee on the subject of animal vaccination are so sensible that I cannot but quote them. They observe that they never contemplated the weakening or annihilation of vaccination from arm to arm, which is and which will be a great benefit for the prophylaxis of small-pox. They only wish for a sanitary reform, which possesses great advantages in guarding infants from accidental but formidable affections, which it would be inhuman to insert into their veins at the same time as the protecting vaccinc virus. $\dagger$

At Gcnoa, the success of revaccinations is $5 \mathrm{I}$ per cent. Genoa possesses a strong garrison; and since 1870 , a third of the recruits have, by (iovernment orders, been revaccinated with animal lymph. The average of positive results has now been raised to 60.95 per 100 .

At Rome, animal vaccinaticn would appear to be practised, although the municipal vaccination service deals only with humanised lymph. It may be of interest to state that, during the twenty-five years $1 \$ 48$ to I $872,22,7$ O vaccinations were performed by the municipality. Of these, 2,488 did not return on the eighth day; and of the remainder, 20, 137 were successful, whilst 14 gave abnormal results and 62 were unsuccess. ful. Thus the proportion of successful results was, in the able hands of Dr. Toscani, as high as 99.62 per 100.

Ancona.-Here both humanised and animal lymph appear to be used. During the four years $1874-7,5,795$ vaccinations $(5,506$ successful) and I, $3 \mathrm{~S}_{4}$ revaccinations (497 successful) were performed with humanised iymph, and 14,044 vaccinations ( 13,021 successful) and 5,316 revaccinations (2,26I successful) with animal lymph. From this station large quantities of calf lymph are sent to the Austrian provinces on the coast of the Adriatic, the provinces on the banks of the Danube, Cireece, and Turkey.

Nafiles.-I have already referred to this city as the cralle of animal vaccination. So far as can be judged from an interesting paper, ${ }_{-\neq}^{+}$recently read by Dr. Serafino before the Sixth Italian Medical Congress, held at Naples last September, animal vaccination would appear to be exclusively practised there. Dr. Serafino shows at some length the reasons why children escape vaccination, and argues strongly for an uniform register of vaccination throughout the kingdom. He also examines the question as to the relative value of the two systems of vaccination (i.c., with humanised and animal lymph); and observes that, if this had to be settled with the statistics collected at Naples, during the epidemic of small-pox of IS7 I and subsequently, the preference must be griven to animal lymph. Indeed, statistics demonstrate that the Neapolitan population, vaccinated with animal lymph, offer a comparatively greater resistance to small-pox than those vaccinated with humanised lymph. From a table appended to his report, I extract the following figures : Births in Naples in 1878 , I 5,190 ; of which 12,828 have been vaccinated, all with animal lymph. Of these, I2,377 were certified as successful (or 96.4 per cent.); in 224 , the result had not been certified; one was spurious; and 226 were unsuccessful.

The animal lymph from Italy would appear, from a report presented to the Constantinople International Board of Health, to have proved of immense service during the Russo-Turkish war. Flying before the invaders, half-a-million refugees from Roumelia arrived at Constantinople, where they remained several weeks before being transported for the most part into Asia Minor. Small-pox made frightful ravages amongst these hordes of people, crowded in the mosques in the villages of the Bosphorus. Measures were, however, early taken to secure their vaccination; and this was promply effected through the supplies of animal lymph sent from Ancona and Naples.

From a valuable memoir, $\$$ by MM. Felice dell' $A c q u a$ and (iionchino Grancini, I take the following general statistics as to animal raccinations in Italy. Excluding the cases that did not return for inspection on the eighth day, the figures as to animal vaccinations performerl in the kingdom since I869, I870, and I87 I, would appear to stand as follows.

* Gas. Mad. Ital. Lomb., No. 90, г877.

+ Foumal d'llysicne, October gth, 1879, p. 4 or.

\$Il Consimento Vacinico della Cittia di Viapoli. I)el Dott. Car. Raflaele Serafino. Napoli: 1879 .

Il Vacino animale $c$ il Vaccino umanizato, Studi sprimentali statistici. Del dottori F. dell'Acqua e G. Grancini. Milano: I $\varepsilon_{79}$. 


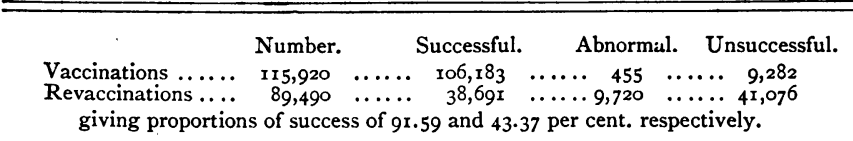

In the year 1877 , the positive results reached at Milan, 99.7 per cent.; at Venice in $1876,99.2$; at Bergamo in 1876, 98.9; and at Ancona, 94 per cent.

Germany.-In this empire, animal vaccination is in great favour, and a large number of institutes at which it is practised are now open.

The first animal vaccination service in Germany was organised at Berlin by Dr. Pissin, in June $\mathbf{1 8 6 5}$, as a private speculation, and is still carried on as such. It happens most opportunely for my present purpose, that Dr. Pissin has recently published a long and most interesting report* on the fourteen years' working of his institute, and I am thus enabled to submit the very latest information with regard to animal vaccination at Berlin. Dr. Pissin's station is not nearly so large as those in Holland, at three of which considerably more than two thousand cases come for vaccination each year ; but it is not less successful. Following the experience of others in the conduct of animal vaccination, Dr. Pissin at first had little success; but he attributes this to his use of M. Negri's system of obtaining the lymph. Subsequently, he went to Paris (in I866); and, after inspecting M. Lanoix's system, adopted the latter in preference to the Neapolitan method. As to his success in vaccinating human subjects, the same initial difficulty has to be recorded. In 1869 , only 46 per cent. of the vaccinations were certified as successful: a proportion, as Dr. Pissin admits, far too small. But doubtless a large number of those which were not recorded as successful did not come back for inspection, since we find Dr. Pissin referring to the favourable change in this respect after the passing of an improred vaccination law in 1875 . Since that year, the percentage of success has been very much greater. In 1875 , it was as nearly as possible 100 per cent.; in 1876 , it was 98 ; in 1877,95 ; and in 1878,97 . For the same years, the ascertained success in revaccinations, which before 1875 were beyond control as regards inspection, was: 1875,$68 ; 1876,72 ; 1877,75 ;$ and 1878,80 per cent. From these figures, Dr. Pissin argues that animal vaccination is quite as successful as humanised vaccination; the more so, as all these vaccinations were not made direct from the calf, but with lymph in tubes, which had been kept for days and even weeks. As to the success of animal lymph in revaccination, which has been particularly observed elsewhere, Dr. Pissin insists strongly; for he says, adverting to the figures given above: "Ein giinstigeres Resultät hat, soviel ich weiss, auch die humanisirte Vaccine nicht aufzuweisen." (P. 20.) Some important tables are given in the report as to the actual number of vaccinations, etc., accomplished; and from these I gather that, during the twelve years $1867-1878,555$ calves were inoculated, 6,773 vaccinations were performed with their lymph at Berlin, and 26,284 tubes were sent away. Dr. Pissin uses, as a rule, one tube for each vaccination; and each calf is made to yield about sixty tubes of lymph. But it is possible, as he says, to get a much larger number of tubes if desired. Most calves yield one hundred tubes, and a good many yield more. Dr. Pissin agrees that animal lymph in tubes is not so effective as humanised lymph; but he states that vaccination direct from the calf on the fourth or fifth day after inoculation is, without exception, effective. To use tube-lymph with success, he advises that simple punctures should not be trusted to, but that cross incisions with broad openings should be made on the arm. In the second quarter of 1866 , the percentage of ascertained success in tubes sent away was 65 per cent.; but since then it has risen considerably, especially since the new law of 1875 , and amongst those vaccinators who use the method of cross incisions. In fact, it is now quite the exception to use punctures or simple incisions. As to the degree of success in the particular case, Dr. Pissin gives the following figures. Of 404 successful vaccinations in a particular period, 56 had one pock, 56 two, 60 three, 69 four, 77 five, and 83 six; the number of incisions being six in each instance. Thus considerably more than half the cases had more than three pocks. On the whole, Dr. Pissin thinks very highly of animal vaccination; and he considers that it can be carried on in Germany as well as in other countries. As to the cost, he reckons that, paying fifteen shillings to the butcher for the loan of the calf, the cost of lymph for each vaccination would be under twopence; but, as the success is only unimportantly diminished by the admixture of glycerine-which, in fact, can be added so as to increase the amount of the lymph five times-each vaccination would only cost a halfpenny. The rent of the stables and of the vaccinationstation, the food and attendance of the animals, and the remuneration of the vaccinator, must of course be added; but these are of a constant

* Bericht iber die vierzehnjährige Wirksamkeit des Impf.-Institutes für animale Vaccination. Von Dr. Med. Pissin. Berlin: 1879 . value and can easily be estimated. The great point for such an institute would be that a weekly cattle-market should be held in the town where it is established, so that the necessary animals could be procured. Dr. Pissin thinks that the Government ought to provide stations for animal lymph; and he recommends that, if the State take the question up, a central bureau should be established, with a head depôt at the largest town in each province. I may add that Dr. Bollinger states in his report that animal lymph is on sale at several dispensaries at Berlin, and at one in Reichenstein (Silesia).

Hamburg. - Animal vaccination was started at the Hamburg public vaccination station in 1875 , by the indefatigable Dr. Voigt. The lymph obtained from Amsterdam at that time is still being used. The lymph is taken from the calves one hundred and twenty hours after inoculation; and the animals are, therefore, kept six days. The cost of feeding each calf for this period on milk (which is constantly tested) is estimated at ten shillings; and a further sum of twelve shillings has to be paid to the butcher from whom it is hired. Dr. Voigt is of opinion that calf-lymph should not be kept longer than a fortnight, and none that has been taken from the calf beyond one hundred and forty-four hours. At the Hamburg station, the proportion of unsuccess with calflymph during 1878 was only 0.29 per cent."

Stuttgart. - Here animal vaccination was commenced in 1875 . The inoculation of the calves is reported to be done on the scrotum, on the ground of the very thin and highly vascular nature of the skin on that part, enabling it to be easily grasped by pincers.

Weimar.-The Medical Association of Thuringia commenced animal vaccination here in 1870 . The calves are mostly inoculated between the vulva and the udder. The proportion of successful vaccination amounted, up to August 1878 , to 89 per cent.; while of revaccinations 80 per cent. were successful.

At Leipsic, animal vaccination has been practised since the end of I877 by Dr. Livius Fürst; at Munich, a station was opened under government patronage by Dr. Kranz on the 2Ist of March of this year; and at Wiirzburg (Bavaria) there is also a station under the charge of Dr. Hofmann. +

AUSTRIA.-At Vienna there are two private institutes, both established in 1877 , one under the direction of Dr. von Heinrich, the other under Dr. Moritz Hay. At Pesth there are several private institutes for animal vaccination.

At Prague, an institute for animal vaccination was started by Dr. Lilienfeld, on the Ist February last, and at a meeting of the Medical Association of Prague, on the 7 th instant, Dr. Lilienfeld gave the result of his vaccinations. $\neq$ Since the commencement of the institute, 273 primary vaccinations have been performed. Of these, 213 were successful and 60 unsuccessful. Doubtless, this large proportion of failure will soon be considerably diminished with further experience, as it seems to be invariably the case that a large number of failures attends the early days of the use of animal lymph.

RUSSIA.-Observations were, early in the history of animal vaccination, instituted in Russia by M. Prosoroft under the direction of the Government. Animal vaccination has now been practised in St. Petersburg for the last ten years under Government auspices by Dr. Bulmerinck.§ Dr. Risdon Bennett, the President of the Royal College of Physicians, who was in St. Petersburg in 1870, states that he saw, in the Foundling Hospital in that city, some rooms fitted up for vaccinating upon and from the heifer, and witnessed and admired there the decent and strict attention to order and cleanliness with which the whole process was conducted.

At Moscow there is also an important station at the Foundling Hospital. In 1869,1870 , and 1871,662 calves were inoculated there, with sixty-four failures.

SiVITZERLAND. - There is an animal vaccination station at Bale under the control of Dr. Siegmund. From the report of the Sanitary Department for 1877 , it would appear that, of 328 vaccinations with animal lymph, twelve were without result; while of 281 vaccinations from arm to arm, eight were without result. At Schaffhausen there is an animal vaccine station, and one is also projected at Zürich.

SPAIN.-Animal vaccination has not yet been officially recognised in this country, but it would appear to be practised at Barcelona.

Des Erfolg mit der Animalen Vaccine in der Hamburger Impfanstalt. Von Dr. Leonard Voigt, Oberimpfarzt in Hamburg. Leipzig: 1879 .

t See Hofmann, "Ueber Impfung mit animale Lymphe". (Aertzl. Intelligenzblatt, p. 22, 1879).

Prager Medicinische Wochenschrift, No. 47, November Igth, 1879

8 A series of interesting papers on Revaccination and Animal Vaccination in St. Petersburg, with a long historical resume of previous experiences of other coun tries in the matter, is now being contributed by Dr. Bulmerinck to the columns of the Munich Aertaliches Intelligenz-Blatt. 
INDIA.-Animal vaccination has made very considerable progress in our Indian empire. It has been practised for several years at Bombay and Poona, and it has at various times been in force at Bhooj (1873-4), Barsi (1874-5, given up in 1875.6), Sakkhar (for three consecutive years in the cold season), Kolapore (1875-6), and Surat (1877-8). Indeed, a Bill is now before the Council of the Governor-General of India, for making the use of animal lymph in ordinary cases compulsory. * Section 13 of the Vaccination Bill of 1879 , introduced by the Honourable Sayyad Ahmad Khán, proposes to enact that "the vaccination of a child shall ordinarily be performed with animal lymph, but in case animal lymph is not procurable, with human lymph; provided the parent or guardian of such child has consented to have the child so vaccinated [with human lymph], or the Governor-General in Council has so directed by notification in the Gazette of India, and has fixed the period for which such mode of vaccination shall be adopted." Nothing was said by the mover of the Bill as to the reasons which prompted him to insist on the universal use of animal lymph; but there seems to be a great prejudice in the minds of the native gentry against allowing lymph to be taken from their children's arms, and the very next clause of the Bill (No. 14) forbids the taking of such lymph without the consent of the parent or guardian. I may here remark that the clause as to animal lymph, which the Honourable Sayyad Ahmad Khán would wish to apply to the whole of India, is already in force in the city of Bombay, under the provisions of Section 12 of the Bombay Vaccination Act of 1877. I am indebted to the kindness of Sir Louis Mallet for the preceding facts, as also for the information which follows as to animal vaccination at Bombay. Sir Louis has indeed most courteously forwarded to me copies of the last reports on the vaccination operations in the whole of the presidencies and districts comprised in the Empire; but in none of these but Bombay does animal lymph seem to be used.

At Bombay, animal vaccination was first started about 1869 by Dr. Ananta Chandroba, Superintendent of the Bombay Presidency Circle; the lymph being brought from Europe by Dr. Blanc, who vouched for its origin and purity. At first, there were a good many failures ; but soon better results were achieved. In 1872 , a special report was presented to the Government by the Superintendent-General of Vaccination, much interest having been excited in the subject, and all the superintendents having previously come either to Bombay or Poona to learn animal vaccination. Meagre as Dr. Pinkerton felt to be the information which he had been able to collect together, he nevertheless reported that it was "entirely in favour of the protective power, purity, and trueness of the animal virus in use". About this time, seventeen practitioners of Bombay, who were asked by Dr. Ananta if they had ever seen or heard of an undoubtedly authentic case of small-pox after vaccination with animal lymph, had to state that none of them could give the name of a single person. Dr. Ananta has devoted immense attention to the subject of animal vaccination, and every succeeding report records better results at his station. In 1872-3, 24I calves were inoculated: 233 with the animal lymph in general use, and 8 with lymph from Dr. Warlomont. Of inoculations with the former, 228, or 97.8 per cent., were successful; with the latter, 2 , or 25 per cent. With 24 exceptions, all the revaccinations were performed with animal lymph. Of 14,940 primary vaccinations, 12,663 were performed with animal lymph, with success in 10,577 cases. Thus the proportion of success was 90.37 per cent. In $1873-4,205$ heifers were inoculated, and 8,285 primary vaccinations were performed, with 7,130 successes, or 89.8 per cent. During $1875^{-6}$, there was an epidemic of small-pox in Bombay; and at the beginning of the year it was found difficult to get calves to supply sufficient lymph to vaccinate the crowds of people who flocked to the station. The effect of this was to lower the percentage of successful vaccinations during part of the year. The number of cows inoculated was 372 , and only II were unsuccessful. Of 19,259 primary operations, 16,853 were performed with calf-lymph, with a percentage of success of 92.65. All the revaccinations but $\mathrm{II}$ were done with calf-lymph, with what success is rot stated. During 1876-7, animal vaccination was continued, to the entire satisfaction of Dr. Ananta. Of 293 heifers inoculated, 287 were successful. In $1877-8,320$ heifers were available, out of a total of 324 . The cost during that year on account of heifers was about $£ 260$, as against $£ 268$ in the previous year. Since the passing of the Compulsory Vaccination Act for Bombay above referred to, all operations in that city are performed with animal lymph, and human lymph is no longer used.

Poonah.-About 1870-I, animal vaccination was practised here by Dr. Blanc. In the report for $1875^{-6}$, it is described as being of much benefit in the way of supplying good and pure lymph. During $1877-8$, there was failure in 3 out of the 60 heifers operated on, the total cost under this heading being about $£ 20$.

* See Gazette of India, October 18th, 1879, page 935:
Surat.-Animal vaccination was introduced here during the rains of 1876 , and continued up to February 13 th, 1878 , when it had to be discontinued, as no heifers could be procured for inoculation. During this period, 35 heifers were used, at a cost of $£ 6$. In 32 of these, the inoculation was successful. The number of primary vaccinations was 273 , and of these 257 were successful, or 90.4 per cent. Revaccinations with calf-lymph were performed on the prisoners in the Surat Jail and eight European inhabitants of that city, and primary vaccinations were performed on the native residents.

UNITED STATES. - The credit of introducing animal vaccination into America belongs to Dr. Henry A. Martin of Boston, who sent specially to Paris for lymph from Professor Depaul, and who was supplied with autograph directions from that distinguished savant. Dr. Martin had secured the use of a farm on which was a herd of nearly fifty young bovine animals, and when, on September $23^{\mathrm{rd}}$, 1870 , he received the virus from the 258 th, 259th, and 260th animals of Dr. Depaul's series, beginning with the heifer of Beaugency, he vaccinated three calves, on the next day two, and so on till he had nearly exhausted his supply of virus in the vaccination of nine or ten animals. In no instance did these vaccinations fail, and Dr. Martin was thus put in possession of ample supplies of animal lymph. The first physician who followed Dr. Martin's example was Dr. F. P. Foster, of the New York Dispensary, who has since established a flourishing service of heifervaccination. Dr. Martin and Dr. Foster had the field to themselves for about eighteen months, after which an epidemic of small-pox produced a demand for lymph so extraordinary, that a great many physicians, to say nothing of dealers, instrument makers, etc., set to work to propagate animal virus. The natural consequence of this haste was, that very large quantities of so-called animal virus were sold, the failure of which did great harm to the cause of animal vaccination. All this time, Dr. Martin was continuing his inoculations with the same care as before, with the result that, after 570 transmissions, he found no tendency to deterioration of the lymph, no shortening of the duration of the induced disease, no indication of change, however slight, from the standard of excellence observed in his first vaccinations six years before. ${ }^{*}$ As over eleven years of constant bovine transmission had elapsed at the date of Dr. Martin's report since the case of cow-pox at Beaugency, without the slightest indication of deterioration, it would seem justifiable to assume that original cow-pox, transmitted through a series of selected young bovine animals, will not manifest the tendency to change which has been noted in virus of long humanisation.

It is a matter for regret that no statistics are forthcoming as to animal vaccination in America, with the exception of some "quasi"-reports, published as business circulars and advertisements, and which are evidently unreliable. It appears, however, from Dr. Martin's report, that, during the six years and nine months that he had practised animal vaccination, he had vaccinated 580 animals, besides some forty more in his early experiments. From these animals, 80,0000 charged points, and an uncounted but very large number of crusts and tubes of fluid lymph - many thousands - have been issued. Virus has been supplied to vaccinate many cities and other municipalities, to a very large number, with quantities of from 500 to 84,000 points. Dr. Martin supplied the Departments of War and the Interior with large quantities of virus, principally in the form of crusts, for the vaccination of troops, frontiersmen, and Indians; and on one occasion supplied 3,000 points for the arrest of an epidemic of small-pox, which threatened the annihilation of an Icelandic colony in British America. In his own practice, Dr. Martin at first experienced, and acknowledged, failure in 20 per cent. of his cases; but he now reports that, with further experience, failure in primary vaccination of infants is a very uncommon event. From the very first, the remarkable success of animal virus in revaccination was generally, indeed universally, admitted-the results of revaccinations, in all cases when the vaccinee has been vaccinated only once before, but at various ages, being exactly 73 per cent. at the first attempt.

Before leaving this part of my subject, it behoves me to refer to the results of an investigation made last year by the eminent professor, Dr. Bollinger, of the University of Munich. $t$ Dr. Bollinger was commissioned by the Government of Bavaria to inquire into the present state of animal vaccination, and for this purpose he seems to have personally visited a large number of the continental stations. As the result of his investigation, he reports himself as very greatly in favour of animal vaccination, and he thinks it gives the very best results. He recom-

* Report on Animal Vaccination to the American Medical Association. ${ }^{1877}$ Vol. xxviii of Transactions, pages $187-248$.

† Ueber animale Vaccination. Bericht über eine im Auftrag des Kgl. Bayer. Staatsministeriums des Innern zum Besuche des Animalen der animalen Impf. Anstalten, etc. Von Dr. Med. O. Bollinger. Leipzig: F. C. W. Vogel. ${ }^{8} 79$. 
mends that large towns should have institutions for the supply of animal lymph, and he regards its universal application as possible. I do not now quote further from Dr. Bollinger's valuable report, but the results of his independent inquiries into the subject seem to me to argue very strongly for the recognition of animal vaccination by the Government of this country, or at all events for a fresh and exhaustive investigations into the improvements effected in it since Dr. Seaton made his adverse report of 1869 .

\section{II.-Examination into Alleged Objections to Animal VACCINATION.}

The objections which have been urged against animal vaccination may be thus briefly summarised. It has been alleged that, $\mathrm{I}$. The vaccinia induced by the use of animal virus is objectionably and even dangerously violent; 2. That animal vaccination is liable to be the means of communicating other animal diseases than that which it is intended to communicate; 3 . That the vaccination of an animal, even with the warm fluid or "living lymph", is an uncertain process, and with tube or dried lymph very likely indeed to fail; 4 . That calf-lymph does not "take" easily on human arms, and that, when it does succeed, the measure of success obtained is not so great as that arising from the use of humanised lymph; 5. That it does not "keep" well; 6. That it is expensive and difficult to obtain. It will be necessary to deal with these several objections a little in detail.

1. Violence.-The fears that the vaccinia induced by the use of calflymph may be objectionably violent are founded not upon actual observations, but on the traditions of the vaccine disease as observed by the early writers. Dr. Seaton has admitted, and it is within my personal observation, that the vesicles produced by calf-lymph are good and well characterised pocks, running the same course, and manifesting the same varieties, as are produced by humanised lymph at the best public vaccination stations in England. Neither in the size of the vesicle, nor in the intensity of the local symptoms, nor in the length of period which the eruption takes to run its course, is there any notable difference. "The cicatrices which I have seen from the action of animal lymph", said Dr. Seaton in 1869 , "are quite characteristic; in depth and foveation, they were as good as the cicatrices ordinarily produced by humanised lymph in the practice of good vaccinators. In short, the result of my personal observations with regard to the animal vaccine lymph in use in London [by Dr. Blanc], in Paris, and at Rotterdam, was that, tested by the character and course of the pocks it produced, it was perfectly good lymph." This frank admission effectually disposes of the first objection. It may be well, however, to add, to avoid possible misconception, that it is well known that peculiarities of local action do attend the use of some stocks of primary cow-lymph, not only in the direct transference of such lymph to the-human subject, but also in its passage through many successive subjects. These local peculiarities are far, however, from pertaining to all original stocks of cow-lymph. In the Bridgwater level and the vale of Gloucester, where the natural disease is not unfrequently seen, Dr. Sanderson states that he has met with many practitioners who have inoculated from such cases, but "that all who have employed such lymph agree in stating that, after the first or second transmission, the results obtained do not differ from those of ordinary vaccination, either in respect to the progress or character of the vesicle."* To argue, therefore, that, because these local effects are manifested in some instances, they must follow in all cases of animal vaccination, is manifestly absurd. The experience of America is in accord with this, for Dr. Martin states that, "in the positive experience of many thousand American physicians, animal vaccination is no more intense than typically perfect vaccination should $\mathrm{be}$, that it is infinitely less liable to be followed by troublesome and irregular sequelæ than that of long humanisation, and that it has, most unexpectedly, but most undoubtedly, proved to be exempt from that miserable complication, the pest of vaccinators, erysipelas."

2. Inoculation of other Diseases. - That animal vaccination may be the means of communicating other animal diseases than that which it is intended to communicate is an exploded bugbear founded on nothing -a revival, in fact, of the " prognostics and denunciations" referred to by $\mathrm{Mr}$. Simon in such eloquent and amusing terms in his masterly "Papers relating to the History and Practice of Vaccination", and so severely satirised by Gilray in one of his best cartoons. It is not a little curious to note that these new objections to the use of animal lymph are the same as the old objections urged in the beginning of the century against humanised lymph. As Mr. Simon has ably said : "Divested of its more ludicrous imagination, all resolves itself into the one not uncommon error of confounding what is fact with what is opinion or inference. A child coughed; to the ears of the vaccinophobist, the sound was as of a cow; to his intellect, it was the effect of vaccination. A child was ugly or squinting, or it had those skin-eruptions which have always been frequent incidents of infancy; at once, to the alarmist, there was vultus taurinus or tinea bovilla. In a word, the oldest and most familiar diseases were thus renamed, in conformity with a belief that vaccination was causing them; while, in reality, there was no more reason in this belief than if vaccination had been charged with occasioning infants to cut their teeth, or with leading boys to prefer cricket to Cornelius Nepos."

We may apply with equal truth these forcible words to the objectors against the purity of animal lymph. A sufficient answer is that there is not an authentic record, hardly even an unauthentic one, of a single case giving colour to the objection in the history of vaccination. The only disease transmitted by animal lymph in Dr. Martin's experience has been a very trivial form of herpes circinnatus, and that can never occur when animals are selected and kept with any approach to ordinary care or propriety. This disease can be remedied at once by the simplest means, and now that it is known, need not recur. Dr. Martin states that at least five thousand calves have been vaccinated during the past seven years in America. "Many of these have been most carelessly selected and improperly kept, but the opponents of animal vaccination will look in vain for any facts to support their dire threatenings and forebodings of disaster.

It is proper that I should mention in this connection that, of course, reasonable care must be taken by the operator in not using lymph that has obviously become putrid. An instance of evil effects arising from the neglect of this most obvious of precautions was recently communicated by Dr. Pietra Santa to the French Academy of Medicine, ${ }^{*}$ and it is right that I should refer to it here. On the 22nd April last, three vaccine pustules were sent to San Quirico d'Orceia by the Vaccination Committee at Rome, these pustules being taken from a heifer inoculated on the 17 th April. Supplies were sent to numerous other places on the same day from the same calf, but no abnormal symptoms followed in the vaccinations performed with the lymph anywhere else than at San Quirico. Here the pustules were used for vaccinations on the 26 th and 28th April. On the first day, eight persons were vaccinated from one of the pustules, which, as the officiating vaccinators admitted, exhaled a mouldy smell. Notwithstanding this, they used the lymph for twentynine persons.

Upon the first eight persons vaccinated, red blotches appeared two hours after vaccination, followed shortly by fever, erysipelas, phlegmons, and suppurating abscesses; the other children, with seven exceptions, also presenting unusual morbid phenomena.

Two inquiries were at once set on foot by the legal authorities and by the General Board of Health of the Kingdom, and it was incontestably proved-I. That the heifer was not ill; $I$. That the virus sent had been of good quality; 3. That, in the three pustules sent to San Quirico, and especially the first, a process of change and of putrefaction had been commenced, so extensive as to have attracted the attention of the operators when only a few of the vaccinations had been performed. The carelessness of the vaccinators in continuing to use the lymph under these circumstances is, to our English ideas, quite inconceivable; and so gross an instance of mala praxis ought not to invalidate for a moment our conclusions as to the value of animal vaccination.

3. Failures in Animals. - There can be no doubt that, at the date of Dr. Seaton's inquiry in 1869 , frequent failures took place in the transmission from animal to animal of lymph derived, in the first instance, from natural cow-pox. But since then very great improvements have taken place in the method of inoculation, so that now to fail in infecting an animal is a very rare occurrence. It must be remembered that in I 869 animal vaccination was in its infancy, and the rules to be observed in selecting animals and in the method of vaccinating them had not then been adequately appreciated. It needs, in fact, to be constantly borne in mind that some amount of care and patience are necessary for the successful cultivation of cow-pox on the calf, as, indeed, for the success of almost any other similar proceeding, however simple. Dr. Warlomont, whose success is now complete, and who can go on with perfect assurance, though inoculating one calf a week only, met at first nothing but aisappointment; and his unsuccesses were so numerous that, had he been guided by the results of his first year's work, he could not but have abandoned the practice. It is not necessary that I should now state how entirely this has been reversed by experience, as Dr. Warlomont will doubtless himself state the results of his inoculations to the Conference. The experience of the Society at Rotterdam supports the same conclusion. They commenced their proceedings in April 1868 by taking a calf to Brussels for inoculation direct from one of Dr. Warlomont's calves. The inoculation was successful; but, after two or three

* Journal d'Hygiène for October 16th, 1879, page 30r. 
months, the eruption on the successive calves became less pronounced, and the Society had, therefore, to send to Brussels for fresh lymph. This acted at first as their original supply had done; but, like it, after a number of weeks' use, apparently deteriorated. The same happened with the supply next obtained; and altogether, between April I868 and June 1869, they had to renew their supply from Brussels at least six times. At length, Dr. Van Vollenhoven went to Paris to consult $M$. Lanoix (who, I believe, has never on any occasion failed in his attempts to continue the disease by inoculation); and, doubtless, profiting by M. Lanoix's experience as to the method of inoculation, brought back with him some mixed Beaugency and St. Mandé lymph of uninterrupted transmission. A degeneration (which I cannot think was only temporary) followed, however, the use of this lymph after a certain time, and recourse was again had to M. Lanoix. Since that time, no difficulty at all has been experienced in keeping up the supply unimpaired, and the lymph now in use at Rotterdam has undergone considerably more than five hundred transmissions without any necessity for renewing the stock. The same experience has been found at other places where animal vaccination was at first found difficult to maintain ; and we are justified in asserting that the difficulty of transmitting successive vaccination from calf to calf does not, or need not, exist.

I cannot refrain, however, from quoting Dr. Martin's remarks in dealing with this objection. He says : "When I commenced the vaccination of animals, I was troubled by apprehensions of failure ; and, in a few instances, did fail entirely. In many, I failed to induce the development of the number of vesicles I desired. I soon found that it was necessary to select animals whose skin was in a good state, wellnourished and vascular, and to exhaust a good deal more time and labour to insure perfect success than I had at first thought necessary. Properly done, vaccination of animals with bovine virus may be said to be invariably successful, so very rare are the exceptions. I think it may be said that a 'stock' of animal vaccine in the hands of a competent propagator is fully as secure from loss as one of humanised lymph. An important fact is, that while to obtain animal virus in the most efficient state for human vaccination, it should be collected at a certain and brief period of the vesicle, that taken at a much later stage of the eruption is found to be quite efficient for the vaccination of other animals. If, as is the best and much the most expensive method, animals are vaccinated directly from each other with warm fluid virus, the operation can be done with more facility than if dried lymph is employed, but still very considerable time and diligence are requisite. When points or quills are used, the labour is much greater, and more time is required to ensure perfect solution of the virus. It must be acknowledged that the vaccination of animals and collection of virus require for their best accomplishment a very decided degree of technical skill, patience, and experience. With these, nothing can be more certain in its results, and failure of animal vaccination conducted by physicians of proper experience need not be feared. The great reasons why Dr. Seaton was led to consider the vaccination of animals a precarious process were that in 1869 , in Europe, tube-lymph was almost exclusively employed, and when points were used they were of a very small size, and on this account were difficult to handle, and held too small an amount of virus. Neither was it then understood how necessary it was to take a good deal of time and care to dissolve the dried lymph and to effect its perfect insertion. To ensure the best results in vaccinating animals, virus should be used very freely, and with patient diligence ; with these, success is very certain."

4. Failures in the Human Subject.-One of the great objections of Dr. Seaton to the use of calf-lymph was its frequent failure to infect the human subject, even when the operation was performed by experienced operators and with lancet direct from calf to arm; and that, when it did take, the measure of success attained was not anything like that attained by vaccination performed from arm to arm at English vaccination stations. Indeed, this may be said to be his principal objection, since whatever may be the advantages or disadvantages of animal vaccination in other respects, the crucial question is how it protects the vaccinee from subsequent small-pox

The difficulty, however, of successfully inoculating the human subject with animal lymph has now been surmounted by experience; and, as will appear from the statistics in another part of this report, animal lymph may now fairly vie with humanised lymph as regards the proportion of successes obtained. But Dr. Seaton has also objected (page 168 of his Report) that a vesicle does not rise to every puncture with the same regularity in animal vaccination as in arm-to-arm vaccination. I regret that no statistics are available to enable me to follow the Medical Officer of the Local Government Board through this argument; but I cannot but think that he has somewhat over-estimated the success systematically obtained throughout England and Wales with humanised lymph. The experience of the National Vaccine Establish- ment was reported by Dr. Seaton to be that, in vaccinations performed from arm-to-arm, vesicles rose in every point of insertion in considerably more than 90 per cent. of the children reported on; that the proportion of cases in which a single vesicle only resulted from the four, five, or more insertions made in each case was about I per cent.; and that failures did not occur on an average above once in 170 times. These results are, however, admittedly obtained only by the most careful and experienced vaccinators we have, and I have reason to believe that throughout England and Wales results of so exceptionally good a kind are not systematically achieved with humanised lymph. I should be the last to decry our present system of vaccination, and I am equally anxious not to say anything that should cast even the slightest slur upon it; but when objections to animal vaccination are based upon the alleged immense superiority of humanised lymph, it may be well to attempt to examine whether this is in fact the case. So far as I am aware no statistics have ever been published showing what is the particular quality of the scars resulting from vaccinations performed throughout. the kingdom at large, and I have therefore had to fall back upon my own resources in attempting, so far as figures will serve me, to find out how much of the vaccination in this country comes up to the official standard of excellence, the grade, in fact, which the Local Government Board designate, for the purposes of grants to public vaccinators, as "first-class", i.e., scars thoroughly well-marked in their foveation, and having collectively at least half a square inch of total area. The results of my calculations are to show that not more than a half of the vaccinations in England and Wales are up to this standard. Indeed, it is notorious, from the experience of all our small-pox hospitals, that a large proportion of vaccinations, although "successful" in the legal sense of the word, are so ineffectually performed as to afford by no means that perfect security against small-pox whith thorough vaccination effects. Into this question, however, it is beyond my present purpose to go ; but, as the statement made above may very possibly be combated, I deem it important to give the figures by which $\mathrm{I}$ have arrived at my conclusion, though $\mathrm{I}$ am afraid that, without a lengthy statement, I shall hardly render myself perfectly intelligible.

If it is objected that my figures relate to different periods, I answer that comparatively little variation takes place from year to year ; and I have endeavoured to make every allowance for differences of this kind. On reference to the last published report of the Local Government Board, I find that, of the 887,694 children whose births were registered in $1876,763,277$ have been successfully vaccinated. Unfortunately, the returns as to the number of public vaccinations performed from year to year are, for some inscrutable reason, made up to the 3 oth September ; but, having regard to the limit of time during which a child is allowed to remain unvaccinated before legal proceedings can be taken, we shall not be out of the way in regarding, as fairly comparable with the 1876 births, the return of public vaccinations performed in the year ended the 3oth September, 1877. From this I find that, during that period, 498,577 public vaccinations were successfully performed on children under one year of age. Now, these public vaccinations would all come under Government review during the years 1877 and 1878 - the inspection of public vaccination in each Union being made biennially; and, for such of them as presented sufficiently satisfactory characters to come up to the official standard of excellence, awards would be given. Adding together the sums gained in this way during 1877 and 1878 ( $\mathrm{I} 1 \mathrm{I}, 994$ and $£ 15,231$ ), and dividing this amount by two, as to exclude the vaccinations of the children born in 1877 , I find that, at the rate of a shilling a case, a total of 272,250 vaccinations were deemed to be so good as to come up to Government standard and deserve recognition. In other words, only 272,250 vaccinations, out of 498,577 public vaccinations performed, were of the first quality. There are several sources of error, however, in this calculation, the arithmetical value of which cannot be measured, and which act in different directions. Thus, some public vaccinators are reported as disqualified from getting awards by their irregularity of attendance, carelessness, etc., though their quality of vaccination may be good; and a few get a less sum for each vaccination than a shilling per case, under circumstances that cannot be detailed. On the other hand, those who do get awards undoubtedly get paid for some cases which are not up to the proper standard, since the Government Inspector can only inspect a certain proportion of cases in order to see the general style of the public vaccinator's work. To examine critically the vaccination scars of half-a-million babies every year would be rather too much to expect of Government inspectors ; and they must, therefore, take a great deal for granted.

On the whole, it may, I think, fairly be said that a little over a half of the number of public vaccinations in England and Wales are of the first quality. But we have to deal, not only with public, but with private vaccinations; and the latter notoriously yield less thorough results than the former. Taking, therefore, the whole of the vaccinations in 
this country in a given year, I think the figures fairly show that, to say that a half only of these vaccinations yield really protective results, is to err on the side of over-estimating the proportion. At the same time, I am conscious that, in this calculation, a great deal has to be taken for granted; and, with a view of clearing up some of the difficulties which still obscure the actual facts, it would seem desirable to procure a Parliamentary return, giving the figures as to each public vaccinator's work, and the reasons which disqualified him for award. This I shall endeavour next session to obtain through the intervention of some friendly member of the Hcuse of Commons.

5. Preservation of Calf-Lymph. - The objection of Dr. Seaton that calf-lymph does not keep well was founded on the fact that, in the early history of animal vaccination, fluid lymph in tubes was alone employed. There can be no doubt that calf-lymph preserved in tubes does not give satisfactory results, unless it be defibrinated by the method now adopted by Dr. Warlomont at Brussels. Dr. Warlomont used formerly to mix the lymph with glycerine, and separate out the more solid matters in the lymph before putting it into the tubes; but he now, by an extremely simple mancuvre, defibrinates the lymph before putting it into the capillary tubes, and nothing is added to it. The tubes, which are of the ordinary capillary sort, are then hermetically closed. Vaccine thus prepared keeps pretty well, but a much shorter time than human lymph collected in tubes. Dr. Warlomont says that one can hardly count upon it for a week; and it is so much the surer in its results in proportion to the shortness of the interval between its collection and its use. For these reasons, Dr. Warlomont much prefers the method of keeping lymph dry on ivory points, which is too well known to be described. The points, first dipped in a solution of cum Arabic, are coated with one, two, or sometimes three applications of lymph. They will then preserve all their power for weeks, months, and even years.

At the Bureau d'Hygiène of Brussels, however, the lymph employed is that purchased at Milan. It is furnished by the contents of the vesicle which has been cut off the calf, and is sent by post in sealed quills mixed with equal quantities of glycerine. This lymph is largely patronised by the best practitioners of Brussels and other parts of Belgium; it is exclusively used at the vaccination-stations of the Hôtel de Ville; and my own observation, as well as all available reports, and the personal assurances which I receive from Professor Hyernaux and other eminent practitioners, testify to its excellence and to its unvarying efficiency.

Dr. Martin expresses a strong opinion that calf-lymph in tubes is unreliable within twenty-four hours after its collection. He does not give the reasons for his views, and I am unable, therefore, to comment on them, except to say that he is probably unacquainted with Dr. Warlomont's mode of defibrinating the lymph. Dr. Martin says that dried lymph on ivory or bone points or on quills keeps as well as any other, and so does the virus in the form of the dried vesicle or scab; this latter, however, seems rather a nasty plan, and I think it is not a desirable way of sending out lymph, except under necessity. Animal virus sent to California every day or two during the summer of 1877 , to the amount of many thousand points, proved, so far as is known, efficient, although much of it was kept nearly three months in that warm climate without particular precaution. Points of animal virus sent also by Dr. Martin to New Mexico, Constantinople, the West Indies, Peru, and to England, are reported by him as having been invariably used with success after arrival.

On the whole, there is a certain weight of evidence in favour of not trusting to tube-lymph, as that on points or quills is equally efficacious, and is not liable to undergo the alterations which tube-lymph may undergo. M. Lanoix, who says that animal vaccine lymph will generally keep in tubes, is in the habit of recommending that it should always be used, if possible, within twenty-four hours of its being taken, and that puncture should not be trusted to for its insertion, but abrasion only employed.

6. Expense.-It may and has been objected that calf-lymph is expensive and difficult to obtain, and that its use will necessitate the devotion of certain persons to its propagation, from whom alone it can be obtained; whilst every primary vaccination affords an abundant supply without any expense or trouble beyond the slight labour of collecting it. But is this altogether an objection? Our object is not to supersede vaccination from arm-to-arm altogether by animal vaccination, but to provide for the frequent renewal from a central office of the stocks by which serics of arm-to-arm vaccinations are commenced, and to facilitate the employment of calf-lymph as an alternative method in cases where parents desire it, or when, from any cause, arm-to-arm vaccination cannot be carried on. It is of very great importance to the profession to be able to draw material for vaccination from a known responsible source, to which all complaints of those vaccinated can be referred; and the alleged expense of propagating calf-lymph, which is, however, much exaggerated, is a reason for its being under the direct supervision of Government, whose interest it would, of course, be to maintain such an institution in the highest state of efficiency.

I have entered into these details in endeavouring to furnish the answers to the objections raised against animal vaccination, because it has appeared to me that these would be the greatest difficulties that would be officially cast in our path in our endeavours to bring about a remodelling of the present National Vaccine Establishment. But I have. thus left myself but little space for the discussion of the advantages of animal vaccination. This, however, is a matter of the less consequence as, at the forthcoming Conference, these advantages will be fully brought out and discussed by others. I therefore confine myself to a mere categorical statement of them. I. Animal vaccine fresh from the calf induces a more perfect development of vaccinia than follows the use of virus of long humanisation. Whatever opinions may be held as to the degree and permanence of the protection afforded by long-humanised vaccination, it can hardly be doubted that the nearer the intentionally produced disease approaches in its phenomena to that casually produced on the hands of milkers, and which has alone been proved to be permanently protective, the safer are we in assuming for it a like permanent protective influence. The opinion is now very widely, though not universally, held, that the results of vaccination are not such as they used to be during the earlier years of the practice of vaccination; in fact, that, by repeated human transmissions, the virus has become weakened, and that the pocks produced by the introduction of lymph which has passed through a large number of human beings are not so fine or so perfect as those which result from the use of lymph derived recently from the cow. It was on this ground that the Commission of the Belgian Academy of Medicine reported in favour of animal vaccination. Jenner himself was not without apprehension that the repeated transmission of vaccine lymph from one human being to another, without recurring to the cow, might impair its virtue; and Mr. Simon has stated some strong reasons for suspecting that the "occasional impermanence of protection may depend upon impairment in the specitic power of vaccine contagion-an impairment arising in the transmission of that contagion through many generations of men".* There seems indeed to be much ground for this opinion; and it is strongly upheld by Dr. Martin, who has devoted immense attention and pains to the subject. 2. The advantage, and in fact necessity, of being able at will to renew a "stock" of vaccine by return to the animal, which can only be had by the maintenance of one or more perfectly reliable services of animal vaccination in continuous operation. 3. It affords means to the physician of tracing the whole pedigree of the lymph he is using; so that doubts as to its quality can be silenced by detailing its entire history. 4 . True bovine lymph is certainly free from all possibility of syphilitic contamination, such as has been alleged against humanised lymph. 5. Animal vaccination can furnish large amounts of lymph regularly and at very short notice. The supply need only be limited by the demand, as all that is needed is a multiplication of the animals vaccinated. One calf alone will furnish sufficient lymph for the vaccination of about four hundred persons. During the late epidemic of small-pox in the metropolis, the medical papers constantly contained complaints of the difficulty of procuring vaccine lymph from head-quarters, and the paucity of the supply when obtained. The vaccination of an extra calf or two on occasion would have saved all this angry remonstrance, as well as much overdraining of vesicles that were used for supplying lymph. 6 . An additional advantage in this connection would be derived from the less frequent occasions on which the vaccinator would be obliged to tap vesicles to obtain lymph, thus allowing the vaccine disease to be developed without interruption in a larger proportion of cases than at present. 7 . True bovine vaccination is, according to the experience of Dr. Martin, entirely free from erysipelas. 8. Animal vaccine induces unmistakable vaccinal effect in a very large proportion (larger, it is alleged, than humanised lymph) of revaccinations. This is a very general experience, though I am not now able to adduce any comparative statistics to prove it. Dr. Martin affirms that the number of those revaccinated with animal virus and virus of very early human removes is, in his experience, a fraction over 80 per cent. - a much larger percentage, it must be confessed, than obtains with lymph of long humanisation. He believes that the difference in the percentage of success of the two lymphs in revaccinations approximately represents the number of those insensible to the enfeebled influence of long-humanised virus, but sensible to the intense contagion of small-pox just in the same degree as sensible to the intense power of bovine virus and that of the very early human removes from it. 9. Calf-lymph produces, in primary

* Papers relating to the History and Practice of Vaccination, p. xxxvi. 
cases, a clear and characteristic scar, equal, if not superior, to the best of those produced by our most careful vaccinators with selected human lymph.

\section{III.-Suggestions For Future Action.}

The reform which I wish to suggest, and up to which the preceding statement leads, is not a very large one, but it is one which, in my opinion, will afford a satisfactory solution of the principal difficulties which are at present felt. Briefly, it is this : that, instead of our National Vaccine Establishment distributing, as it does at present, lymph of long humanisation, it should distribute only lymph direct from the calf, in the same way as the Belgian Institut Vaccinal de l'État. By this means, medical men who are obliged to appeal to Whitehall for material to start their vaccinations would not feel that they were inoculating their patients with matter of which they must take the previous history for granted, and the Government, on the other hand, would be able to assert much more satisfactorily than it can at present that the lymph which it sends out is absolutely pure. Any subsequent mischance must necessarily be due to the carelessness of the operator himself, and the present shifting of blame from one person to the other could not take place.

Under such a system, the Government would establish a central vaccinal establishment at which a small series of calves would be maintained, and from week to week fresh vaccinations of such heifers would be made. This would take the place of the two vaccination-stations now maintained by Government, the services of the present able vaccinators being retained for this new work. The lymph collected would be distributed upon demand, as at present, without payment to public vaccinators, for maintaining arm-to-arm vaccinations at their stations, and to all registered private practitioners on payment of a small fee, such a sixpence per tube or per ten points, a rate of payment now recognised by the Local Government Board under certain circumstances. In this, the public vaccinators would always have at their command, for the service of new stations, a s!.pply of lymph of undoubted purity of source and protective energy ; while the private prastitioner could for an insignificant sum secure for his patients the like privilege. This would place the vaccination system of the country on a larger and firmer basis than it now occupies, and would relieve both public and private vaccinators from many of their present difficulties, while it would cut away all solid ground for that mischievous agitation against vaccination which gives so much trouble to legislators and magistrates, and does much to interfere with the means necessary for the extinction of small-pox.

No doubt an objection will be made here, based on a supposed great increase of expense that will ensue from the cultivation of calf-lymph by the Government. Let us see how this argument is borne out by facts. Our present National Vaccine Establishment costs the country $£ I, 700$ a year. Of this, $£ 400$ is spent on the salary of an assistant-inspector; $£ 300$ on the remuneration of two vaccinators; and $f_{\mathrm{I}}, 000$ for the purchase of lymph, ivory points, tubes, and other apparatus. Now, I have the authority of the opinion of Dr. Warlomont for the assertion, and, after personal examination of all the facts, I have no doubt, that for $£ \mathrm{I}, 000$ a year a perfectly satisfactory animal vaccine service could be established in London. It seems to me a very reasonable estimate ; and, even allowing a considerable margin in excess of it, it will be seen that the reorganisation of our present system so as to supply from headquarters animal vaccine only would be productive of little, if any, additional expense to the country. All this could not be done in a day. No doubt much care, patience and experience must be brought into play before perfectly successful results can be attained; but that they are attainable is, I hope, manifest from what has preceded.

I must apologise for the length of this report; but, in entering into these details, I have been actuated by the desire to lay before the Committee, and through it to the Conference and those who may take part in it, as complete an examination of the subject as is possible within reasonable limits of space. I trust that the particulars which I have collected and the conference which, with the authority of the Committee, I have succeeded in organising for Thursday next, the 4 th instant, at 4 P.M., at the rooms of the Medical Society of London, may be of some assistance in facilitating the discussion, and in securing a long-wanted reform in our English vaccination system.

Offices of the British Medical Association, I6ra, Strand, W.C., November 26th, 1879.

The Cavan Board of Guardians, in a false spirit of economy, have refused to ratify a recommendation of the Belturbet Dispensary Committee to appoint a qualified midwife for that district, and in consequence have been informed by the Irish Local Government Board that a sealed order will be forwarded compelling them to do so.

\section{SURGICAL MEMORANDA.}

\section{THE CLOVE HITCH.}

THE description of this knot, illustrated by a woodcut in the last number of the JOURNAL, represents the knot called a clove hitch and half a hitch. This knot has been in use among sailors from time immemorial. Its mode of application by Mr. Tait is novel; still, however it may be formed or applied, there it is-our old familiar friend-the ordinary clove hitch with half a hitch.

George Roper, M.D., Finsbury Circus.

\section{CLINICAL MEMORANDA.}

\section{A CASE RESEMBLING LOCOMOTOR ATAXY.}

THE following case, which bore some resemblance to locomotor ataxy, will, I have no doubt, be interesting. Mrs. M., aged 57, applied for treatment for debility and dyspepsia. In the course of examination for these complaints, she stated that she suffered from pain in the right frontal and temporal regions, and in the left arm, the last being in the course of the musculo-spiral nerve and its branches. She also stated that she had flying pains and spasmodic jerkings in the leg, and that the latter disturbed her a good deal during sleep; that she had weakness of the eyelids, especially the left, which, when awaking from sleep, she was unable to open for some minutes; this I found to be the case on awakening her one day at my visit. There was no ptosis visible, however, after some minutes elapsed from the time of her getting out of sleep. Another symptom to which she directed my attention was a difficulty she experienced when walking, as any irregularity of the ground made her stumble, and, to avoid which, she was obliged to watch every step. She could stand without support, but not if she closed her eyes. When she placed her feet together, she had great diffculty in maintaining her equilibrium; but, if she shut her eyes, she immediately fell down. Her walk was slow, and free from the unsteadiness characteristic of ataxy. I failed to detect any inco-ordination of movement, anæsthesia, etc.

The patient was treated with nourishing diet, stimulants in small quantities, five-grain doses of quinine three times a day, and a blister to the nape of the neck. Under this treatment, she quite recovered her health.

REMARKs. - The principal symptoms were the following :

I. The neuralgia and shooting-pains require notice, on account of their being frequently among the premonitory symptoms of ataxy.

2. The liability to stumble also deserves to be mentioned, as it is a well known fact that an ataxic individual has great difficulty in walking on uneven ground.

3. The inability to stand when the feet were placed together, and more especially, if the eyes were closed. This condition is always present in ataxy, and is an important diagnostic test for it. Trousseau says : "If you ask an ataxic individual to stand up, and keep his feet closely applied together along their inner edges, he manages to do it with some difficulty when his eyes are open, even at an early stage of the disease ; but, when he shuts his eyes, he immediately oscillates, and falls down." And he regards it of greater importance in diagnosis than the irregularity of the patient's walk. Niemeyer considers it a valuable test. Dr. Bristowe says that it "becomes evident in the most marked manner in the very earliest stage of the disease, when the patient is made to stand blindfold with his feet together. At once he begins to totter and to sway, and, unless he opens his eyes or is supported by others, soon falls to the ground." Dr. Wilks, too, while maintaining its diagnostic value, states that it is seen in cases where this disease is absent.

It is an interesting fact that the inability to stand in the manner above stated is not due to debility, but (so far as my small experience goes) is only observed in those suffering from cerebral derangement. In support of these statements, I will succinctly relate two cases. A man, aged 50, had suffered from debility for a considerable time when I began attending him. He had to keep his bed to avoid getting an attack of syncope; while in this condition, he stood up easily with his feet together and his eyes shut. The other was a woman aged 6o, suffering from melancholia, with marked suicidal tendency, who fell down whenever she put her feet together. 